\title{
Subtyping meconium protease activities which degrade lung protective angiotensin converting enzyme- 2 in human lung cells
}

\begin{abstract}
Purpose: Meconium pneumonitis occurs due to local lung injury and inflammation in newborn with meconium aspiration. The activation of Renin Angiotensin System (RAS) plays critical role in lung injury. Angiotensin converting enzyme-2 (ACE 2) functions as a negative regulator of the angiotensin system by converting pro-apoptotic Angiotensin II to anti-apoptotic Angiotensin 1-7. Our previous study has shown that meconium causes degradation of lung protective ACE-2 by proteolytic enzymes present in meconium. However, the specific proteases in meconium that degrade ACE- 2 have not yet been identified.
\end{abstract}

Objective: To begin characterizing ACE-2-degrading proteases in meconium through the use of different subtypes of protease inhibitors.

Methods: Alveolar epithelial A549 cells were exposed to F-12 medium, 2.5\% meconium and meconium + specific protease inhibitors (PIs). Specific PIs used included chymostatin, AEBSF(Pefobloc) and leupeptin. At the end of incubation, cell lysates were collected for ACE-2 immunoblotting and enzyme activity.

Results: Reduction of ACE-2 immunoreactive 100-115 kDa bands or enzymatic activity by meconium was attenuated by treatment with chymostatin, but not with the other the PIs. These data suggest the involvement of cysteine-like proteases in meconium in ACE2 degradation, and suggest a potential therapeutic strategy of PI administration to babies aspirating meconium.

Keywords: renin angiotensin system, angiotensin converting enzyme-2, meconium aspiration syndrome, meconium-stained amniotic fluid
Volume 8 Issue 3 - 2021

\author{
Naisha Chokshi,' Amal Abdul-Hafez, ${ }^{2}$ Bruce \\ D Uhal ${ }^{2,3}$ \\ 'Division of Neonatology, Department of Pediatrics \& Human \\ Development, Michigan State University, East Lansing, USA \\ ${ }^{2}$ Department of Physiology, Michigan State University, USA
}

\author{
Correspondence: Bruce D Uhal, Department of Physiology, \\ Michigan State University, 3197 Biomedical and Physical Sciences \\ Building, 567 Wilson Road, East Lansing, MI, 48824, USA, \\ Email uhal@msu.edu
}

Received: August 17, 2021 | Published: September 03, 2021

\section{Introduction}

With advancement in technology and new strategies in management, the incidence of Meconium Aspiration Syndrome (MAS) has decreased in the last few years. However MAS still is one of the major causes of respiratory distress in term and post-term newborns, and around $3-4 \%$ of newborn are affected with MAS..$^{-3}$ Clinical symptomatology and severity varies anywhere from mild chemical pneumonitis to pneumothorax and/or severe pulmonary hypertension. ${ }^{4}$ Understanding the mechanism of the lung injury in MAS would help to guide for better management of the condition. ${ }^{5-10}$ Meconium is a sticky dark green substance containing gastrointestinal secretions, bile, bile acids, mucus, pancreatic juice, blood, swallowed vernix caseosa, lanugo, and cellular debris. ${ }^{4}$ The pathophysiology of meconium aspiration is a complex series of events, including mechanical effects, direct toxic chemical effect as well as inflammatory effect due to various inflammatory and proinflammatory factors., ${ }^{41,12}$ Studies on animal models have shown inflammatory processes, cell death and apoptosis in meconium aspiration and exposed the role of the renin-angiotensin system (RAS) in inflammation as well as in lung injury in response to meconium. ${ }^{13-19}$

Angiotensin converting enzyme-2 (ACE-2) is an integral part of RAS and converts the octapeptide ANG II to the hepta-peptide ANG
1-7 (20-22). The ACE-2/ANG1-7/Mas system has antiapoptotic, anti-inflammatory, antifibrotic and vasodilatory, and acts through the "Mas receptor," which inhibits the actions of Angiotensin II. Meconium causes degradation of the lung protective enzyme ACE-2 by proteolytic enzymes present in meconium. ${ }^{23}$ Previous studies from this laboratory have shown that the detrimental effect of meconium on lung cells caused by pancreatic proteolytic digestive enzymes present in meconium can be reversed by a protease inhibitor cocktail. Protease inhibitor cocktails contain various subtypes of protease inhibitor including chymostatin, AEBSF, leupeptin, E-64, aprotinin, benzamidine, phosphamidon, and aminohexanoic Acid. ${ }^{24}$ Chymostatin, one subtype of protease inhibitor, showed protective effects against meconium exposed lung cells in vitro. ${ }^{23-26}$ The effect of subtypes of protease inhibitors on ACE 2 has not yet been studied. Therefore, the aim of this study was to identify the subtypes of protease inhibitors which prevent degradation of ACE-2 by meconium proteases.

\section{Methods}

Cell culture: The human lung adenocarcinoma A549 cell line was grown, maintained, and handled according to the supplier's manual in Ham's F 12 medium (American Type Culture Collection, Manassas, VA), with $10 \%$ fetal bovine serum (FBS; GIBCO, Grand Island, NY), as described earlier. ${ }^{27}$ Data from our laboratory showed that ACE-2 
expression is cell cycle dependent and maximum at postconfluent (quiescent) densities. ${ }^{28}$ Therefore, we used cells 5 days postconfluence for experiments.

Meconium preparation: We used previously collected firstpass meconium from anonymous healthy babies, collected under protocols approved by the Michigan State University Institutional Review Board. ${ }^{29}$ This undiluted meconium was preserved and stored in small $\cong 1 \mathrm{~g}$ aliquots at $-80 * \mathrm{C}$. On the day of experiment, meconium was thawed at room temperature, diluted to $10 \%$ (wt/vol) with Ham's F 12 medium, and dispersed by vigorous vortexing for $10 \mathrm{~min}$. The resultant suspension was centrifuged at $3000 \mathrm{~g}$ for $20 \mathrm{~min}$ at $4^{\circ} \mathrm{C}$. The supernatant was further filtered and sterilized using a $22 \mathrm{~m}$ filter and then used in the experiments. Initial test of meconium effect on the A549 cells. The cells were exposed to meconium diluted in serumfree Ham's F 12 medium to final concentrations of $2.5 \%$.

Subtype of protease inhibitor storage and preparation: Roche Protease Inhibitors Set $(11206893001)$ was stored at $4 * \mathrm{C}$ prior to use. Dilution was different subtype of protease inhibitors were done as per manufacturers guide lines. Prepared PIs were stored at-20*C with 1 month stability. See Table 1 for specific PIs and their final concentration in cell culture. We choose these PIs as our previous study has showed chymostatin has maximum protective effect from cell detachment in meconium exposed cells followed by AEBSF and leupeptin. ${ }^{24}$

Cell treatment: Confluent A549 cells after 5 days culture were used for treatment. All subculture experiments were performed in serumfree medium. Subtype of PIc (Roche, Nutley, NJ) to final desired concentration as mentioned above were diluted in $2.5 \%$ meconium and serum-free media. The cells were incubated to: a) serum free medium (control), b) 2.5\% meconium, c) 2.5\% meconium and one subtype of protease inhibitors - Chymostatin, AEBSF and Leupetin, and d) subtype of PI alone for 16 hour at $37 *$ c. For Chymostatin experiment, same concentration of DMSO was added to serum free media (control) to. Triplication of all conditions were done to validate the observed results. At the end of the incubation period, cells were assayed for ACE-2 by immunoblotting for reactive protein and for ACE-2 enzyme activity. Ice cold NP-40 lysis buffer was used to prepare the cell lysate and was maintained on cold on ice for immediate experiment.

\section{Western blotting}

$10 \%$ Tris HCL polyacrylamide gels, were used for western blot. Gel well were loaded with $40 \mu \mathrm{g}$ of protein lysate and separated by SDS-PAGE, in 10× Tris/glycine/SDS buffer. After separation of Proteins in gel, they were transferred to Polyvinylidene Difluoride "PVDF" blotting membrane. Prior to treating with primary antibody, blocking was done by $5 \%$ nonfat dry milk in $0.1 \%$ tween 20 in Trisbuffered saline. Binding with primary antibodies using polyclonal antibody against C-terminal amino acids of Human ACE2 (Abcam Catalog Ab15348) was performed. PVDF membrane was incubated with ACE-2 antibody for $16 \mathrm{~h}$ at $+4^{\circ} \mathrm{C}$. $\beta$-actin (Cell Signaling Technology, Danvers, MA) was used to normalize the assay. To visualized the bands HRP-conjugated goat antirabbit antibody were used as secondary antibodies and bands were seen using enhanced chemiluminescence detection by standard autoradiographic film techniques.

ACE-2 enzyme assay: The cell lysate of chymostatin-subtype of PI treatment was also analyzed for ACE-2 enzyme activity. A549 cells were harvested in ice-cold complete Tris- $\mathrm{HCl}$ buffer $(\mathrm{pH}$ 6.5), $1 \times$ Complete PIc EDTA-free and lisinopril $(50 \mu \mathrm{g} / 1$; SigmaAldrich). Lisinopril was added to the buffer to block the ACE activity. Fluorogenic substrate for angiotensin converting enzyme-2 (ACE2) - MCA-APK (Dnp) (Enzo Life Sciences, Farmingdale, NY) was added at a final concentration of $10 \mu \mathrm{mol} / 1$ to $30 \mu \mathrm{l}$ cell lysate (in a total volume of $50 \mu \mathrm{l}$ ) on ice. DX600, a competitive inhibitor of ACE-2, was added to half of the wells to compare enzymatic ACE-2 activity inhibition. The plate was warmed to room temperature, and the fluorescence was read on a plate reader $(310 / 20 \mathrm{~nm}$ excitation and $420 / 50 \mathrm{~nm}$ emission) in a FL600 Microplate Fluorescence Reader (BioTek, Burlington, VT) for $30 \mathrm{~min}$. Using surface-enhanced laser desorption/ionization time of flight mass spectrometry (MS) with Protein Chip Array technology, ACE2 activity was measured.

Statistics: ACE-2 protein/b-actin assay analysis data are shown as mean \pm SEM. Comparison between meconium vs meconium with one subtype of PI was done using student's test. One-way analysis of variance (ANOVA) with Student-Newman-Keul's post hoc test was used for group comparisons of ACE-2 enzyme activity in chymostatin treated experiment. $\mathrm{P}<0.05$ was considered significant.

\section{Results}

A549 cells, when $90-95 \%$ confluent, were incubated with meconium and various subtypes of protease inhibitors. Figure 1 shows the effect of meconium and different subtypes of protease inhibitors on A549 cells. Under microscopic examination (Figure 1A) shows that cells when treated/exposed with meconium, became rounded and eventually detached from the cell culture plate. But when cells were treated with meconium plus chymostatin (Figure 1B) or meconium or AEBSF (Figure 1D) they stayed attached to the cell culture plate and had preserved morphology. Treatment of cell with meconium plus leupeptin (Figure 1C) did not show comparable preservation of attachment with cell culture well as compared to chymostatin and AEBSF.

We next studied the effect of these subtypes of protease inhibitors on ACE-2 in meconium treated/exposed A549 cells. Figure 2 shows protection of meconium-induced proteolytic cleavage of ACE-2 by chymostatin. Immunoreactive ACE-2 appears at $\sim 100-115 \mathrm{kDa}$ by Western blot. In our previous study, ${ }^{29}$ the degradation of $100-115 \mathrm{kDa}$ ACE-2 by meconium produced a $37 \mathrm{kDa}$ proteolytic clip of ACE-2 (not shown) and thereby reduced the amount of 100-115 kDa ACE-2. In Figure 2, chymostatin increased the apparent amount of the 100$115 \mathrm{kDa}$ ACE-2 band in the presence of meconium by preventing its degradation (Fig X in 29). Figure 3 shows densitometric quantitation of the effects of chymostatin, AEBSF and leupeptin on preventing the reduction of the 100-115 kDa form of ACE-2 in the presence of meconium. Only chymostatin, but not AEBSF or leupeptin, were capable of preventing the reduction of immunoreactive 100-115 kDa ACE-2 $(\mathrm{p}<0.01)$.

Next we evaluated the enzymatic activity of ACE-2 in A549 cells treated with meconium or each of the protease inhibitor subtypes. As shown in Figure 4, chymostatin could prevent the meconiuminduced decrease in ACE- 2 enzymatic activity $(p<0.01)$. Interestingly, chymostatin alone appeared to slightly reduce ACE-2 enzymatic activity when applied alone $(\mathrm{p}<005)$, suggesting that the protective effect of chymostatin observed in the presence of meconium may have been underestimated in the assay conditions employed here. 

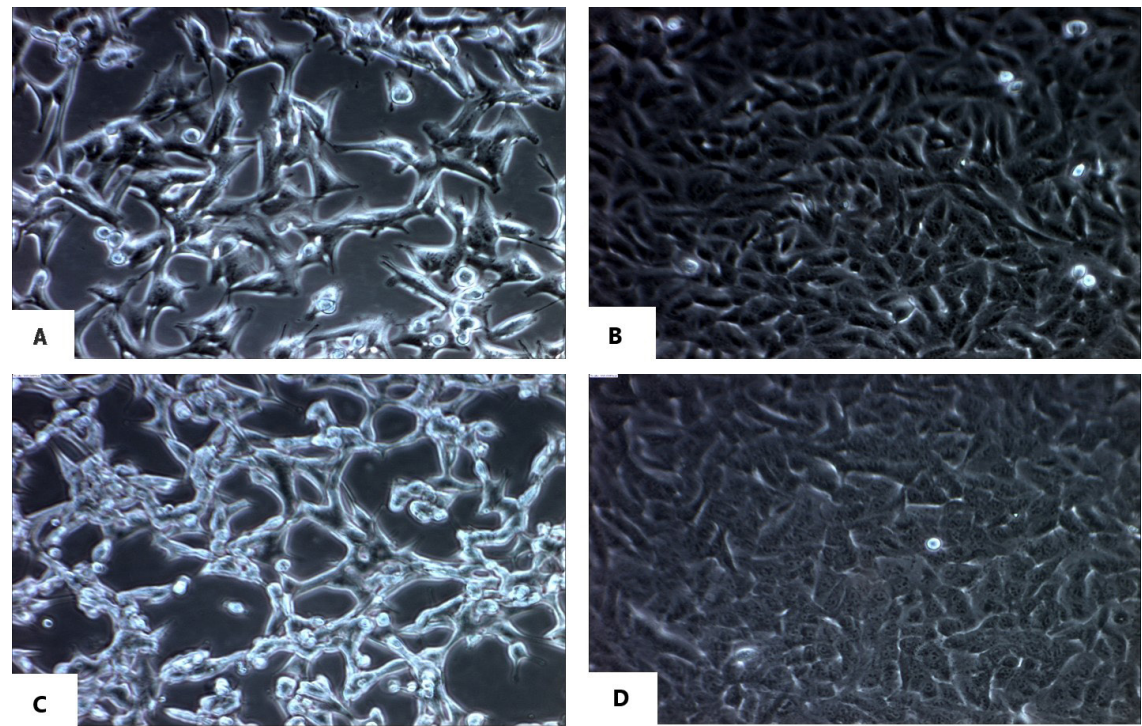

A549 cells treated with A- meconium , B -meconium and Chymostatin C- Meconium and Leupeptin D- meconium and AEBSF

Figure I Effect of protease inhibitors on lung epithelial cell detachment in vitro.A549 cells were cultured in the presence of $2.5 \%$ meconium and each of the following protease inhibitor subtypes: Panel A: no protease inhibitor (+ meconium); Panel B: meconium + chymostatin; Panel C: meconium + leupeptin; Panel D: meconium + AEBSF. See text for details.

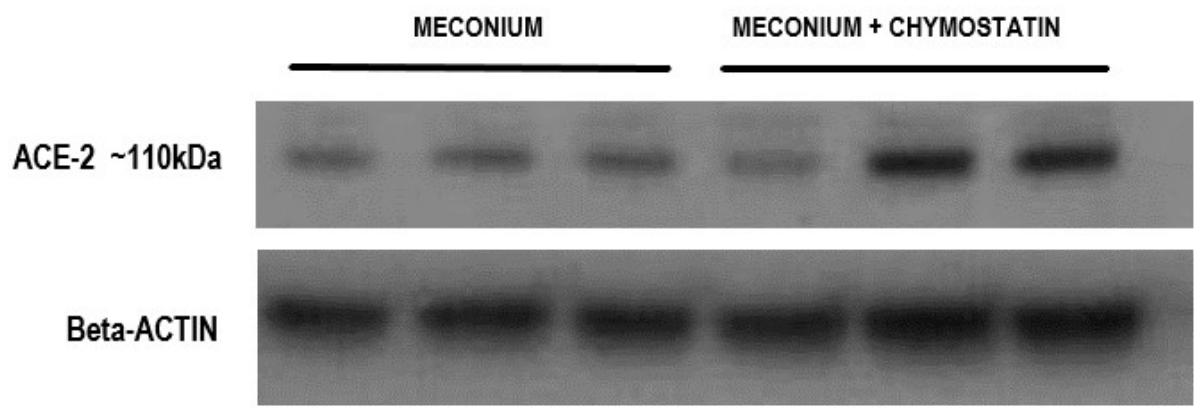

Figure 2 Protection of immunoreactive ACE-2 from meconium-induced degradation by chymostatin. A549 cells were cultured in the presence of meconium, with and without chymostatin. After $20 \mathrm{hrs}$, cell lysates were analyzed by western blotting for immunoreactive ACE-2, 100-1 I $5 \mathrm{kDa}$ form. Note increase in ACE-2 $100-115 \mathrm{kDa}$ band with chymostatin. See Figure 3 for densitometry and statistics on multiple samples with several protease inhibitors.

\section{Effect of Chymostatin on ACE-2 Protein in A549 Cells in the Presence of Meconium}

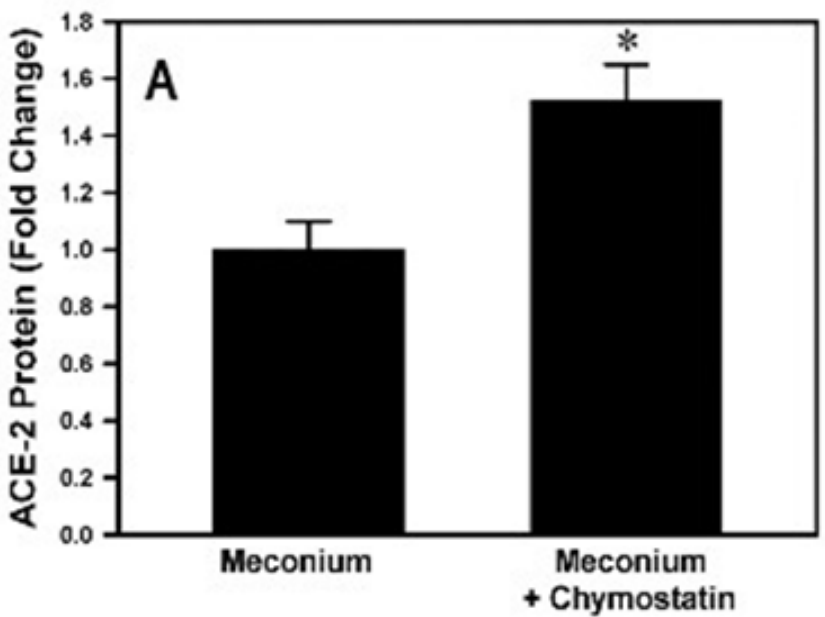

Effect of AEBSF on ACE-2 Protein in A549 Cells in the Presence of Meconium

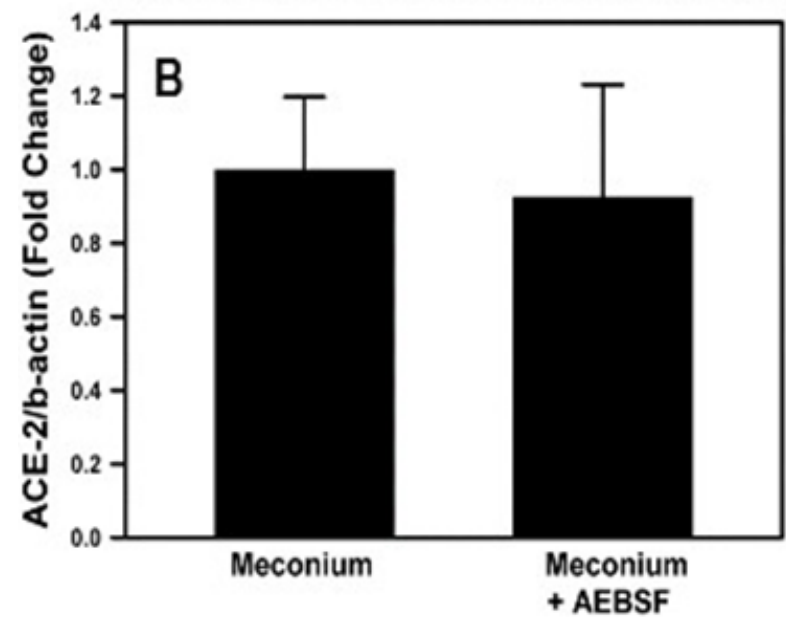

Citation: Chokshi N,Abdul-Hafez A, Uhal BD. Subtyping meconium protease activities which degrade lung protective angiotensin converting enzyme-2 in human lung cells. J Lung Pulm Respir Res. 202I;8(3):I I3-I I8. DOI: I0.15406/jlprr.2021.08.00262 
Effect of Leupeptin on ACE-2 Protein in A549 Cells in the Presence of Meconium

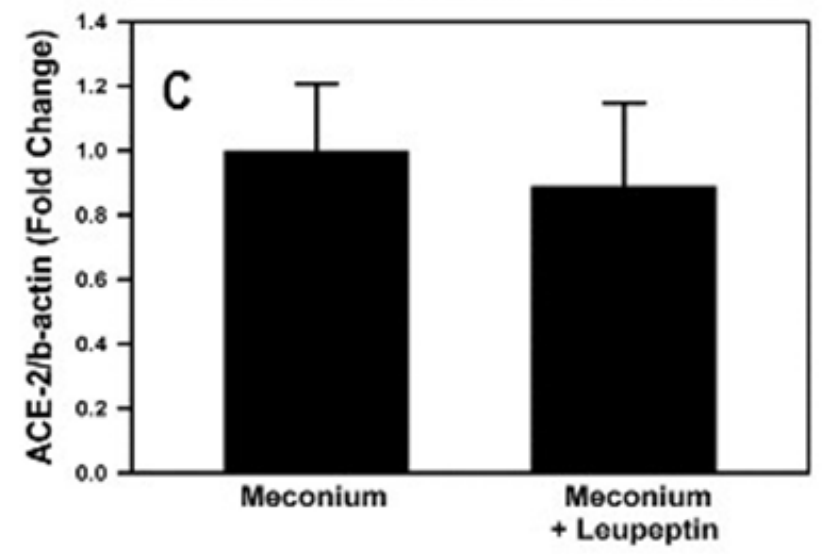

Figure 3 Densitometric quantitation of the effects of three protease inhibitor subtypes on meconium-induced ACE-2 degradation. A549 cells were cultured in the presence of $2.5 \%$ meconium, with and without the protease inhibitors chymostatin (Panel A), AEBSF (Panel B) and leupeptin (Panel C). Note statistically significant increase in ACE-2 (protection from degradation) with chymostatin (Panel A), but not with AEBSF or leupeptin. See text for details.

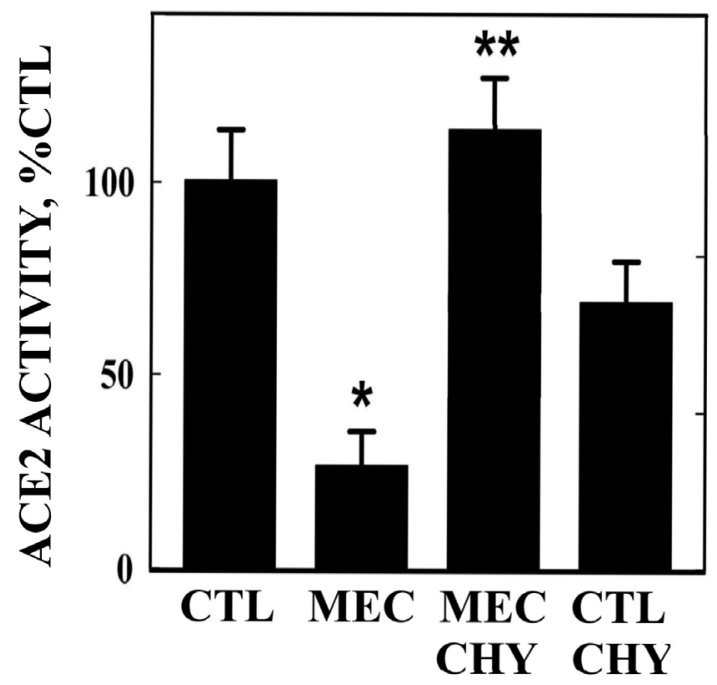

Figure 4 Protection of ACE-2 enzymatic activity from meconium-induced degradation by chymostatin. A549 cells were cultured in $2.5 \%$ meconium with and without chymostatin, AEBSF or leupeptin. Note reduction in ACE-2 enzyme activity by meconium alone (MEC), but protection by coincubation with chymostatin (CHY). AEBSF or leupeptin (not shown) had no significant protective effect on enzymatic activity.

\section{Discussion}

Meconium aspiration syndrome (MAS) is defined as respiratory distress in a neonate born through meconium-stained amniotic fluid (MSAF) having characteristic radiological changes whose symptoms cannot be otherwise explained. ${ }^{30}$ Despite collaboration between obstetricians and pediatricians in prevention of MAS over the time, MAS remains common problem. ${ }^{31}$ In the United States, the reported incidence of MAS varies from 0.1 to 0.4 percent of births. The incidence of symptomatic MAS was 0.25 percent and asymptomatic MAS was 0.1 percent based on newborn discharge data in 2012 from the Kids Inpatient Database (KID). MAS occurs in approximately 2 to 10 percent of infants born through meconium-stained amniotic fluid
(MSAF) ${ }^{32-34}$ MAS accounts for about $10 \%$ of cases of respiratory failure in all neonates, and is associated with significant morbidity and high mortality (up to $39 \%$ ). ${ }^{35}$ Despite improvement in obstetrical and neonatal care, MAS continues to be a neonatal disorder with high morbidity and mortality.

The lung injury caused by meconium is complex and can be attributed to mechanical obstruction of airways, surfactant inactivation, chemical pneumonitis, and PPHN. ${ }^{35}$

The exact pathophysiology of MAS has not been yet elucidated completely. It is likely a complex process starting in utero, possibly a consequence of a chronic exposure with several mechanisms involved, from small airway obstruction to surfactant dysfunction with several pathways of inflammation activated. ${ }^{36,37}$ Nevertheless, MAS may be regarded as a multifactorial disease with various pathophysiologic processes, the bulk of available evidence suggests that meconium is a potent activator of inflammatory cascades via several of the various chemical components constituting meconium . Role of the arachidonic acid pathway, various cytokines like TNF, IL-6, IL-8, the nuclear factor $\kappa \mathrm{B}(\mathrm{NF}-\kappa \mathrm{B})$ family, the complement factors and immune modulators (e.g. cyclooxygenase- 2 and nitric oxide synthase) has been shown by various experimental studies to play role in inflammatory process in MAS. ${ }^{12}$ Previous concepts that described MAS primarily as a direct consequence of aspiration during delivery are now being questioned as various new concepts have emerged in our understanding of the pathogenesis. ${ }^{38,39}$

Lung inflammation and apoptosis of alveolar epithelial cells (AECs) are important pathogenic components in the development of MAS. ${ }^{40-42}$ The fetal pancreatic digestive enzymes present in meconium likely play a role in the lung damage after meconium aspiration..$^{40,43,44}$ Exposure of A549 cells to meconium resulted in significant disruption of connections between A549 cells and cell detachment. Various studies have shown roles of Renin Angiotensin System (RAS) in pathophysiology of meconium aspiration. ${ }^{45-50}$ The involvement of Fas or TNF-alpha in meconium-induced apoptosis is known to require Angiotensin II generation. ${ }^{16,17}$ Lukkarinen et al. ${ }^{13}$ showed the Angiotensin II receptor blockade inhibits pneumocyte apoptosis in experimental meconium aspiration; in contrast intratracheal captopril did not present significant beneficial effects on severe meconiuminjured lungs after injury. ${ }^{19}$ The studies from this laboratory showed role of RAS in meconium induced lung injury and degradation of lung protective angiotensin converting enzyme- 2 by meconium in human alveolar epithelial cells. ${ }^{18,23}$

It was shown in earlier work that protease inhibitors offer protection against meconium-induced lung epithelial injury. ${ }^{16,26} \mathrm{~A}$ protease inhibitor cocktail containing chymostatin, or chymostatin by itself, showed significant protective effects on A549 cell detachment induced by meconium. But other subtypes of protease inhibitor (AEBSF, leupeptin, E-64, aprotinin, benzamidine, phosphamide, and amino hexanoic acid) did not offer statistically significant protection.

Here we confirmed the effect of meconium on A549 cells causing cell detachment, and among three subtypes of protease inhibitors, chymostatin and AEBSF showed significant protective effects in preventing cell detachment but leupeptin did not (Figure 1). In contrast, only chymostatin, but not AEBSF or leupeptin, protected ACE-2 immunoreactive protein and enzymatic activity (Figures $3 \& 4)$. These data suggest that the specific meconium-borne proteases that effect cell attachment are different from those that degrade ACE2. Variability of different meconium samples with respect to potency for cell detachment and ACE-2 degradation (data not shown) also 
suggests that different babies meconium samples may vary in the amount or character of proteolytic enzymes. This possibility, as well as different babies pancreatic protease genotypes, will comprises interesting topic for future investigation. Regardless, the results reported here, strongly suggest a potential role for chymostatinlike protease inhibitor preparations in the treatment of Meconium Aspiration Syndrome.

\section{Conclusion}

- These data suggests that the inhibition of chymotrypsin-like serine-type proteases, Cathepsin like cysteine proteases can reduce the degradation of lung protective $\mathrm{ACE}-2$ by proteolytic enzymes.

- Increasing ACE2 activity through serine and cysteine protease inhibitors might therefore be a novel approach for the treatment of meconium-induced lung injury.

- Needs confirmation in animal models of MAS.

\section{References}

1. Whitfield JM, Charsha DS, Chiruvolu A. Prevention of meconium aspiration syndrome: an update and the Baylor experience. Proc (Bayl Univ Med Cent). 2009;22(2):128-131.

2. Lee J, Romero R, Lee KA, et al. Meconium aspiration syndrome: a role for fetal systemic inflammation. Am J Obstet Gynecol. 2016;214(3):366. e1-e9.

3. Thornton PD, Campbell RT, Mogos MF, et al. Meconium aspiration syndrome: Incidence and outcomes using discharge data. Early Hum Dev. 2019;136:21-26.

4. Fanaroff AA. Meconium aspiration syndrome: historical aspects. $J$ Perinatol. 2008;28(3):S3-87.

5. Chettri S, Bhat BV, Adhisivam B. Current concepts in the management of meconium aspiration syndrome. Indian J Pediatr. 2016;83(10):1125-1130.

6. Khatua S, Serrao PR, Milano EL. Advances in management of meconium aspiration syndrome. Indian J Pediatr. 2000;67(11):837-841.

7. Roberton NR. The management of meconium aspiration syndrome. Turk $J$ Pediatr. 1991;33(2):65-78.

8. Srinivasan HB, Vidyasagar D. Meconium aspiration syndrome: current concepts and management. Compr Ther. 1999;25(2):82-89.

9. Swarnam K, Soraisham AS, Sivanandan S. Advances in the management of meconium aspiration syndrome. Int J Pediatr. 2012;2012:359571.

10. Wiswell TE. Advances in the treatment of the meconium aspiration syndrome. Acta Paediatr Suppl. 2001;90(436):28-30.

11. Cleary GM, Wiswell TE. Meconium-stained amniotic fluid and the meconium aspiration syndrome. An update. Pediatr Clin North Am. 1998;45(3):511-529.

12. Lindenskov PH, Castellheim A, Saugstad OD, et al. Meconium aspiration syndrome: possible pathophysiological mechanisms and future potential therapies. Neonatology. 2015;107(3):225-230.

13. Lukkarinen H, Laine J, Lehtonen J, et al. Angiotensin II receptor blockade inhibits pneumocyte apoptosis in experimental meconium aspiration. Pediatr Res. 2004;55(2):326-333.

14. Rosenfeld CR, Zagariya AM, Liu XT, et al. Meconium increases type 1 angiotensin II receptor expression and alveolar cell death. Pediatr Res. 2008;63(3):251-256.

15. Uhal BD, Abdul-Hafez A. Angiotensin II in apoptotic lung injury: potential role in meconium aspiration syndrome. J Perinatol. 2008;28(3):S108-112.
16. Wang R, Zagariya A, Ang E, et al. Fas-induced apoptosis of alveolar epithelial cells requires ANG II generation and receptor interaction. Am J Physiol. 1999;277(6):L1245-L1250.

17. Wang R, Alam G, Zagariya A, et al. Apoptosis of lung epithelial cells in response to TNF-alpha requires angiotensin II generation de novo. $J$ Cell Physiol. 2000;185(2):253-259.

18. Zagariya A, Bhat R, Chari G, et al. Apoptosis of airway epithelial cells in response to meconium. Life Sci. 2005;76(16):1849-1858

19. Zagariya A, Bhat R, Navale $\mathrm{S}$, et al. Inhibition of meconium-induced cytokine expression and cell apoptosis by pretreatment with captopril. Pediatrics. 2006;117(5):1722-1727.

20. Imai $Y$, Kuba K, Rao S, et al. Angiotensin-converting enzyme 2 protects from severe acute lung failure. Nature. 2005;436(7047):112-1126.

21. Imai $Y$, Kuba K, Ohto-Nakanishi T, et al. Angiotensin-converting enzyme 2 (ACE2) in disease pathogenesis. Circ J. 2010;74(3):405-410.

22. Kuba K, Imai Y, Penninger JM. Angiotensin-converting enzyme 2 in lung diseases. Curr Opin Pharmacol. 2006;6(3):271-276.

23. Gandhi C, Uhal B. Roles of the angiotensin system in neonatal lung injury and disease. Invited Review. JSM Atheroscler. 2016;1(1):1014.

24. Ivanov VA, Gewolb IH, Uhal BD. A new look at the pathogenesis of the meconium aspiration syndrome: a role for fetal pancreatic proteolytic enzymes in epithelial cell detachment. Pediatr Res. 2010;68(3):221-224.

25. Lisowska-Myjak B, Pachecka J. Trypsin and antitrypsin activities and protein concentration in serial meconium and feces of healthy newborns. $J$ Matern Fetal Neonatal Med. 2006;19(8):477-482.

26. Ota C, Gopallawa I, Ivanov V, et al. Protection of Meconium-Induced Lung Epithelial Injury by Protease Inhibitors. J Lung Pulm Respir Res. 2017;4(5):145.

27. Zagariya AM, Bhat R, Zhabotynsky E, et al. Characterization of serine/ cysteine protease inhibitor alpha1-antitripsin from meconium-instilled rabbit lungs. J Cell Biochem. 2005;96(1):137-144.

28. Uhal BD, Dang M, Dang V, et al. Cell cycle dependence of ACE-2 explains downregulation in idiopathic pulmonary fibrosis. Eur Respir $J$. 2013;42(1):198-210.

29. Gandhi CK, Holmes R, Gewolb IH, et al. Degradation of Lung Protective Angiotensin Converting Enzyme-2 by Meconium in Human Alveolar Epithelial Cells: A Potential Pathogenic Mechanism in Meconium Aspiration Syndrome. Lung. 2019;197(2):227-233.

30. Natarajan CK, Sankar MJ, Jain K, et al. Surfactant therapy and antibiotics in neonates with meconium aspiration syndrome: a systematic review and meta-analysis. J Perinatol. 2016;36(1):S49-s54.

31. Fanaroff AA. Meconium aspiration syndrome: historical aspects. $J$ Perinatol. 2008;28(Suppl)3:S3-7.

32. Whitfield JM, Charsha DS, Chiruvolu A. Prevention of meconium aspiration syndrome: an update and the Baylor experience. Proc (Bayl Univ Med Cent). 2009;22(2):128-131.

33. Lee J, Romero R, Lee KA, et al. Meconium aspiration syndrome: a role for fetal systemic inflammation. Am J Obstet Gynecol. 2016;214(3):366.e1-9.

34. Thornton PD, Campbell RT, Mogos MF, et al. Meconium aspiration syndrome: Incidence and outcomes using discharge data. Early Hum Dev. 2019;136:21-26.

35. Swarnam K, Soraisham AS, Sivanandan S. Advances in the management of meconium aspiration syndrome. Int J Pediatr. 2012;2012:359571.

36. van Ierland $\mathrm{Y}$, de Beaufort AJ. Why does meconium cause meconium aspiration syndrome? Current concepts of MAS pathophysiology. Early Hum Dev. 2009;85(10):617-620. 
37. Lindenskov PH, Castellheim A, Saugstad OD, et al. Meconium aspiration syndrome: possible pathophysiological mechanisms and future potential therapies. Neonatology. 2015;107(3):225-330.

38. Chettri S, Bhat BV, Adhisivam B. Current Concepts in the Management of Meconium Aspiration Syndrome. Indian J Pediatr. 2016;83(10):1125-1130.

39. Choi W, Jeong H, Choi SJ, et al. Risk factors differentiating mild/ moderate from severe meconium aspiration syndrome in meconiumstained neonates. Obstet Gynecol Sci. 2015;58(1):24-31.

40. Ivanov VA, Gewolb IH, Uhal BD. A new look at the pathogenesis of the meconium aspiration syndrome: a role for fetal pancreatic proteolytic enzymes in epithelial cell detachment. Pediatr Res. 2010;68(3):221-224.
41. Zagariya A, Bhat R, Chari G, et al. Apoptosis of airway epithelial cells in response to meconium. Life Sci. 2005;76(16):1849-1858.

42. Zagariya A, Bhat R, Uhal B, et al. Cell death and lung cell histology in meconium aspirated newborn rabbit lung. Eur $J$ Pediatr. 2000;159(11):819-826.

43. Whitcomb DC, Lowe ME. Human pancreatic digestive enzymes. Dig Dis Sci. 2007;52(1):1-17.

44. Lisowska-Myjak B, Pachecka J. Trypsin and antitrypsin activities and protein concentration in serial meconium and feces of healthy newborns. $J$ Matern Fetal Neonatal Med. 2006;19(8):477-482. 